\title{
How to Deal with Student Misbehaviour in the Classroom?
}

\author{
Xinrui Yuan (Corresponding author) \\ School of Software, Dalian University of Foreign Languages \\ 6 South Lvshun Road, Dalian 116044, China \\ Tel: 86-411-8611-1150Ｅ-mail: xinrui_yuan@yahoo.com.cn
}

Ling Che

The Department of Second Foreign Languages, Dalian University of Foreign Languages

6 South Lvshun Road, Dalian 116044, China

Tel: 86-411-8611-1167Ｅ-mail: checheteaching@yahoo.com.cn

Received: January 17, $2012 \quad$ Accepted: March 5, $2012 \quad$ Published: May 1, 2012
doi:10.5539/jedp.v2n1p143
URL: http://dx.doi.org/10.5539/jedp.v2n1p143

The research is financed by Liaoning Higher Education Society, China. No. WYZDB11020.

\begin{abstract}
Student Misbehaviour in the classroom is a tough and unavoidable task to the teachers and it takes up teachers' considerable time to deal with. The paper tries to define and classify classroom misbehaviour, and then attempts to generally analyse the main reasons that cause students misbehaviour in the classroom from three aspects: the students, the teacher and the society, then according to the seriousness of misbehaviour it gives some suggestions of appropriate steps to control the problem effectively, from preventing to punishment, to build good student-teacher relationship and assure the teaching and learning progress.
\end{abstract}

Keywords: Misbehaviour, Classroom, School, Student, Teacher

\section{Introduction}

For many teachers, dealing with student misbehaviour in the classroom takes up a considerable proportion of teaching time, which in turn affects the quality of the student's learning experience. Surveys have generally indicated that behaviour problems have become progressively more important to schools (Long, 2000). The aim of this paper is to discuss how to deal with student misbehaviour in the classroom.

In order to solve a problem, the root of the problem is the key to the solution. That is to say if the reasons why students misbehave are better understood, the will be in a better position to create conditions in which there is less need or fewer opportunities for such behaviour (Robertson, 1996). McManus (1995) points out that troublesome behaviour cannot be understood without considering it in several spheres: individual, family, classroom, school, community and the whole society. Student misbehaviour cannot be seen as an isolated factor although it mainly happens in the classroom. It has to been analysed according to the whole environment of the children's life. After defining what student misbehaviour is, the paper will classify the causes of student misbehaviour into three main sources: the students, the teacher and society.

After exploring the reasons for the problem, it is not very difficult to find the ways in which a teacher might cope more effectively. The paper is going to explain teacher behaviour continuum, which is a series of responses to student misbehaviour in the classroom, according to seriousness. Especially two factors will be focused on: rewards and punishments, which are two effective teachers' actions towards the type of misbehaviour which does not happen accidentally.

As Kyriacou (1997) suggests, the key task facing teachers is to minimise the occurrence of student misbehaviour in the first place, which is called pre-empting the misbehaviour. Besides a practised classroom management skill of teachers, the student-teacher relationship plays an important role in dealing with student misbehaviour as well 
as on the existence of misbehaviour. It is very important to build a positive relationship with children in order to avoid their negative behaviour in the classroom.

\section{What is Student Misbehaviour in the Classroom?}

Kyriacou defines student misbehaviour as "any behaviour that undermines the teacher's ability to establish and maintain effective learning experience in the classroom" (1997:121). Kyriacou (1997) ranges student misbehaviour from simple non-compliance (e.g., not paying attention) to overt disruptive behaviour (e.g., throwing a missile across the room). He also points out that serious misbehaviour, including direct disobedience, physical aggression or damage, is much less frequent. Table 1 shows the frequency of disruptive student behaviour.

From Table 1, it can be seen that serious misbehaviour, physical aggression, verbal abuse especially to teachers, is rather less frequent; while the "vast bulk of student misbehaviour is quite minor in nature" (Munn et al., Wragg, cited in Kyriacou, 1997). Each range of student misbehaviour has its own special causes. The next part will discuss the causes of student misbehaviour, especially focusing on those less serious but more frequent classroom incidents. All teachers need to deal with student misbehaviour occasionally. The ability to deal with student misbehaviour is essential to teachers because this kind of behaviour is a threat to good discipline and requires effective management.

Hollin (1993) states several reasons why student misbehaviour is problematic:

1) It provokes and offends members of the teaching profession;

2) It is detrimental to the educational progress of the "bad child";

3) It may have untoward effects later in the child's life;

4) It may hinder and disrupt the educational and social progress of "good children" who share a classroom with "bad children".

\section{The Causes of Student Misbehaviour in the Classroom}

In order to solve the student behavioural problems in the classroom, it is essential to discuss the causes firstjust where does it come from? Some social scientists argue that student misbehaviour has less to do with the characteristics of students and more to do with the behaviour of teachers (Stephens and Crawley, 1994). It is true that students' behaviour can be provoked by teachers' actions, but it is not the whole reason. Most of the causes of student misbehaviour in the classroom can be traced back to three main sources: the children, the teachers and society.

\subsection{Causes of Misbehaviour I: the Children}

\subsubsection{Attention Seeking}

As pointed out by Erik Erikson (1963, cited in Fontana, 1993), the need to gain and hold the attention of others appears to be a general human characteristic. Some children try to gain the attention of others, such as parents or teachers, by being natural and friendly when they grow up in positive environments; on the other hand, some children find they can gain the attention of others by anti-social behaviour (e.g., being impatient or angry) rather than by social behaviour. For example, a little girl is very good to help her mother to make some pancakes, but she cannot understand why her naughty younger brother who is always a "trouble-maker" gains the privilege of being given the first pancake by her mother, while she doesn't receive any praise. In this case, when she finds the "bad" behaviour does work to gain the attention of others, and will possibly try to behave not as well as before.

Fontana (1993) states that as a child grows older and starts school, the situation is made worse by the fact that he or she may have anti-social behaviour patterns further reinforced rather than discouraged. This is because the teacher may have little time to watch carefully and respond with attention and praise for the child who produces correct behaviour. Instead of praising the "good behaviour", the teacher will spend most of time "catching the child behaving badly", and attempt to instruct him or her against unacceptable behaviour. The reactions of the teacher will probably "encourage" a large amount of misbehaviour in the classroom that is only because of students' attention-seeking. McManus (1993) suggests that the teacher must try to give the student attention when he or she is engaged in acceptable behaviour; and, so far is possible, unacceptable behaviour must be ignored or given minimal attention.

\subsubsection{Learning Difficulties}

It cannot be denied that there is a strong association between learning difficulties and behaviour problems. Kyriacou argues that "the most common trigger for student misbehaviour seems to be encountering learning 
difficulties which threaten the student's self-esteem" (1997:124). It is not difficult to find that children who have some behaviour problems often have low levels of basic academic skills. A typical study by Wilgosh and Paitich (1982, cited in Long, 2000) found that more than 60 percent of a sample of 99 girls and boys who were delinquents at about 14 years of age were underachieving by two or more years in at least one area of academic skills.

It is easy to understand that people tend to do their best at the things in which they are successful, and normally lose their interest in those things where even though they make their efforts, thus fail constantly. When children find themselves performing well in the classroom and get praise and rewards from the teacher frequently, they will have a positive feeling about school and themselves and will be willing to work hard and cooperate with teachers. On the other hand, the children who have difficulties with their work will be probably unsatisfied with themselves and will have a negative feeling about school and the classroom work. Constant failures of attainment will definitely threaten their self-esteem; they easily doubt their ability to master the new work. Being unable to manage any formal work in the classroom, they might easily turn their efforts to other activities, such as talking with other children, which would be called disruptive behaviour in the classroom.

The association of learning difficulties and misbehaviour might make the children's long-term development of literacy get worse. On one hand, learning difficulties, which might originally be from children finding lessons boring and losing interest in them, is one of the main causes of student behaviour problems in the classroom. On the other hand, early behaviour problems that prevent children from being involved with schoolwork will limit their progress with literacy skills (Adams et al, 1999; Long, 2000). This has been demonstrated by the study by McGee et al. (1986, cited in Long, 2000) with 925 boys from 5 to 11 years of age. The main finding was that those children who had early behaviour problems at age 5, particularly poor concentration and attention, subsequently had low levels of learning progress. As they became older, the types of their behaviour difficulties changed and they became more antisocial.

\subsection{Causes of Misbehaviour II: the Teachers}

Before talking about the relationship between a teacher's performance and student misbehaviour in the classroom, please allow me to give an example from the very beginning of my teaching experience. I began my formal teaching experience in a primary school when I was a fourth year student at university and taught English there as a part-time teacher. Firstly I thought it could be very easy for me to teach English to 9-year-old children, because I did not think I would meet any academic problems, and also I was sure I could build a very good relationship with the children because I believed myself a kind person. But after two days I realised teaching was far more difficult than I assumed. The first problem I met was that my kind smile did not play a good role in the teaching procession because I could not draw the students' attention when I taught with a kind smile. Some of them even talked with each other occasionally when I was teaching. The second problem was that in the first two classes some children could not understand what I was saying because I taught them using adult language and spoke quickly which was obviously too difficult for them to follow. After two days failure, I tried to change my teaching style to make my teaching more effective. I tried to be a little strict as other experienced teachers were, and made an effort to use very simple words to explain slowly and clearly. Several days later I found the outcome was quite satisfactory. The misbehaviour in the classroom was becoming much less and the knowledge I taught seemed to be understood by a majority of the children.

It is obvious that I made two mistakes in the class at the beginning that caused the misbehaviour: one is I misjudged the relationship between teachers and students, the other is the way I presented the lesson was not suitable for the children's ability, age and interests.

There is some truth in the assertion that children's misbehaviour in the classroom is a reaction to the teachers' behaviour towards them, which is "unacceptable" to the students; in another words, teachers' actions can provoke students' misbehaviour. Marsh et al. (1978, cited in Kyriacou, 1997) highlighted four types of teacher behaviour which student's particularly felt "provoked" them into misbehaviour.

These are:

- teachers who are boring

- teachers who could not teach

- teachers whose discipline was weak

- teachers who made unfair comparisons

These suggested some of the common reasons for student misbehaviour that are linked to the teachers' actions, 
which can be simply classified into three reasons that can lead to children's bad behaviour in the classroom. These are: the teacher's authority, the teacher's ability to exercise the necessary classroom control and the teacher's personality.

"An essential aspect of effective teaching is the need for a teacher to establish and maintain authority over the organisation and management of students' learning" (Kyriacou, 1997: 101). In order to control discipline of the classroom, a teacher must try to make his authority be accepted by the students. A positive friendship must be built upon the respect of the students. At the beginning, when introducing oneself to students, friendliness can be seen as a sign of weakness, and a teacher can easily lose the respect of his/her students. In this situation, misbehaviour in the classroom seems unavoidable. The right way is trying to build a positive relationship after a teacher's authority has been accepted by his students.

Fontana (1994) gives six issues which influence the degree to which a teacher is able to exercise the necessary class control.

These are:

- physical appearance

- voice

- the way in which the teacher presents the lesson

- lesson preparing and organization

- the way in which teacher talk to children

- the way in which threats, rewards and punishments

In addition to these factors, a teacher's authority and the ability to exercise the necessary classroom control, a teacher's personality characteristics also play an important role in the classroom control that definitely influence the student behaviour in the classroom. A teacher who is kind, warm and judges the students" behaviour fairly can easily earn the respect from the students, and build a positive relationship with the children. Otherwise, a teacher's unfair or impropriate action can provoke student misbehaviour because as Kyriacou (1997) points out, student misbehaviour is in large measure an attempt to maintain their sense of self-dignity in the circumstance that confront them.

Many studies have shown that students are sensitive to how teachers behave to them, and it is easy to see how some students may see their own misbehaviour simply as a fair and legitimate reaction to the teacher's teaching (Kyriacou, 1997:124). Kyriacou (1997) suggests that "all teachers need to be aware of how their behaviour can serve to hinder rather than facilitate good discipline in the classroom".

\subsection{Causes of Misbehaviour III: the Society}

It is impossible, of course, to entirely separate out personal problems from social ones. Student's problem behaviour in the classroom cannot be isolated from the factors that originate from society.

Children who have not formed a proper judgment about right behaviour because of their age and social experience normally tend to imitate the behaviour around them, which can be explained as social learning theory.Social learning theory proposes that many behaviours develop as a result of our observing what other people do, which is a key concept in understanding how children develop their knowledge of social role and their sense of identity in school (Long, 2000). From social learning theory, it is not difficult to assume that children's viewing of violence on television can be causally linked with subsequent aggressive behaviour.

Another point is family influence, which has been established beyond reasonable doubt that the family can play crucial role aetiology of bad behaviour (Loeber and Stouthamer, 1986; West, 1982, cited in Hollin, 1993). A study from Fergusson and Lynskey (1997, cited in Long, 2000) with 1,265 children in New Zealand from the point of school entry to the age of 16 shows that children with behaviour problems generally had poor home backgrounds, including a high chance of belonging to a low social class, a high chance of coming from a single-parent family, and a high chance of coming from a poorly managed home. A study with 113 at risk students in 25 secondary schools in Malaysia indicates that most of the misbehaviors of at risk students are related to family problems, such as lack of parental monitoring, poor interactions in the family and problems associated with low income families (Elias et al. 2009).

The family environment along with the parents' educational style and attitude to the children may affect student bad behaviour. For example, as Hollin argues (1993), erratic rewards and punishments delivered by parents make it unlikely that the child will be strongly motivated towards academic achievement, which might be the root of 
some bad behaviour as argued before. In addition, he includes that children's misbehaviour can be seen to have its origins in the quality of parenting as evinced by erratic discipline, parental disharmony, and the modelling and approval of bad behaviour.

\section{Dealing with Student Misbehaviour}

\subsection{Pre-empting Misbehaviour}

While a number of studies seek the actions to deal with student misbehaviour that has appeared in the classroom theoretically and practically, Kyriacou (1997) suggests "preventing" rather than "curing" the bad behaviour in the classroom by the skill of "vigilance plus action", in which vigilance involves the teacher monitoring the students' behaviour and appropriateness of the learning activities, and action is what the teacher does to sustain students' academic engagement in the learning experience whenever it seems to have problem. In this way, the incident level of misbehaviour can be avoided.

In addition, he suggests establishing clear rules and expectations in regard to classroom behaviour, which is a crucial aspect of pre-empting misbehaviour (Kyriacou, 1997: 125). Teachers should be very clear about the classroom rules when they first meet their new class, which can be easily made if the teacher's authority can be established and accepted (Kyriacou, 1997), this also can help new teachers, especially student teachers, establish their authority as well. A proper teacher-student relationship can be easily developed with students accepting teachers' authority; meanwhile, the frequency of misbehaviour in the classroom can be avoided before it happens. Pre-empting misbehaviour can make the teaching and learning progress smoothly and effectively and also help to establish an appropriate relationship between teacher and students.

\subsection{Teacher Behaviour Continuum}

Regarding the misbehaviour at the individual level, teachers should find out the reasons of the improper behaviour first and then the response should move along a continuum according to the perceived seriousness of the interruption (see Figure 1). From Figure 1, we can see that the teachers' reaction should be according to the seriousness and the reasons for the children's misbehaviour in the classroom.

Silently looking on can be used simply for observation and soaking in the information in the classroom without any attempt at changing the behaviour, or it may make the student who attempts to draw his/her attention from the learning know that the teacher is noticing what is happening. Ignoring is the least response which teachers make to misbehaviour, which Rogers (1997) names as tactical ignoring, and can be an appropriate teacher response to some misbehaviour, because at the very least it avoids "over-servicing" attention-seeking.

If the student misbehaviour becomes a little bit more serious than non-verbal misbehaviour, for example, fiddling or doodling and not paying attention, then the verbal intervention through non-directive statements, questions and directive statements will reflect progression along the continuum (Cooper et al, 1994). These three steps are defined by Rogers (2002) as distraction/diversion, direct question and command. Examples given by Wolfgang and Glickman (cited in Cooper et al, 1994) rang from the non-directive statement, "I saw you throw the book", through questioning, "Why are you doing that?" to the directive statement "don't do that again!" Children are often not consciously aware of why they do things and just repeat actions which have been effective in the past (Long, 2000). Asking children to explain the reason for their behaviour can lead them to be aware of their mistake and avoid children repeating the misbehaviour. Wolfgang and Glickman suggest that teachers should be ready to give academic support to students who behave inappropriately because of the academic difficulty, rather than confront them over the misbehaviour itself.

\subsection{Rewards and Punishments}

Before analysing the differences and conflicts between rewards and punishments, I would like to give an example here: It still happened in the same primary school as I mentioned in part 2 . There were two classes, A and B, which interested me most whilst I taught English there, because of the obvious contradistinctions between them two. I could find hardly any difficulties while I was teaching in Class A, the students there behaved appropriately, cooperatively, and showed their interests in the class work, and it was very easy for me to build a positive relationship with them. The complete opposite, Class B seemed like a nightmare to me: bad behaviour in the class was so common that I had to stop to reinforce discipline frequently, it was quite hard to get them to focus on the class work, and to make friends with them. I was curious about the differences of the two classes in which the children were the same age. Later I found the only difference was the attitudes of the supervisors of the two classes: the supervisor of Class A was a girl who was kind and positive, she always praised the children in her class, while the supervisor in class B was a girl who was extremely strict with her children students, never smiled, and punishment was the main method of dealing with the misbehaviour in the classroom frequently. So 
the students in Class B were quiet when she was in the classroom, and hard to control as soon as she left. A more serious fact was that the children in Class B often showed their "hostility" to the teachers. I believe that is an example about the different effects of rewards and punishments on the student behaviour in the school. As Adelman and Taylor (1990) state that it necessary to make great efforts to have students view the teacher as supportive (rather than hostile and controlling or indifferent).

Kyriacou (1991) defines punishment as "in essence a formal action which the student is intended to experience as unpleasant as a means of helping them to behaviour appropriate in the future". Punishment, which is called a kind of negative control, is frequently used in the classroom by teachers because of it is a "quick fix" and can work well (Long 2000). Punishment, as the last and most serious and formal action which can be used by teachers, is effective in controlling the classroom when it is used appropriately, but it is not easy to define what appropriate punishment is. Because of the shortcomings of punishment (for example, it can lead to confrontation and threaten the student-teacher relationship etc. see the example above), teachers are advised to use punishment carefully and to avoid using it if student misbehaviour can be dealt with by other actions.

When punishment is frequently used by a number of teachers, it is well documented that the teachers as a group are not praising and rewarding the students much (Munn et al, 1992). It might be because that with negative control (punishment), you respond only to the misbehaviour, whereas with positive control (reward), you have to go out of your way to look for and reward the good behaviour (Long, 2000). But it is easy to find that offering appropriate rewards to children will make the chances of shaping their behaviour much easier, because a simple definition of a reward is something that appears desirable to peoples concerned, while punishment, by the contrast, is something that appears undesirable (Fontana, 1994). Appropriate rewards may be more effective than punishment in dealing with some misbehaviour in the classroom.

I would like to give another example here. I can still remember a boy in the class I taught who was always a troublemaker. Punishments were not effective for him at all even though they were used frequently by some of his teachers. Nobody liked him because he was not good at studying and always behaved badly in the classroom including in my English class in the beginning. The situation changed one day when by chance I asked him to stand up and read a text before the class. I can realise that some students were smiling a little bit and preparing to laugh at him because I knew nobody believed he could read the text fluently. To my surprise, he read the text quite well according to his academic level. Without thinking too much, I put my book down and applauded him, and all the other students began to applaud him too. Blushing a little, he gazed at me and smiled. From then on I found he did not behave as badly as before in my English class and he made big progress in English.

An appropriate reward can deal with students' misbehaviour which is caused by low self-esteem. A reward can help students build their self-confidence and avoid their misbehaviour in the classroom. Also a quick and spontaneous reward for good behaviour can be more effective than punishment of bad behaviour because the former can naturally affect misbehaviour at the same time. A reward for good behaviour is an example to other students and can provoke other students to behave appropriately by the "competition consciousness" among the students. On the other hand, punishment, as a negative control, can definitely give not only the student concerned but also all the students fear and anxiousness, because the other students will be afraid of being punished by repeating the same mistake.

In a word, punishments and rewards, no matter how small, play a large part in moulding and directing student misbehaviour in the classroom. Although as discussed before, punishment has some shortcomings, it might be still the only effective action to some extremely troublesome behaviour. So it should be used appropriately in order to maintain a positive classroom phenomenon.

\section{Conclusion}

Dealing with student misbehaviour in the classroom is a tough and unavoidable task for teachers, because on one hand, it results from a large range of causes that originate from the environment around the students: the individual, classroom, school, community and the whole society. It makes the teachers have to understand the sources before dealing with the unacceptable behaviour. On the other hand, there are no stereotypes for solving the problem, because children are different from each other, which makes teacher give different responses to each individual child. An inappropriate reaction to student misbehaviour will make the problem get worse and affect the teaching and learning progress more.

But the difficulty and the unavoidability do not make the problem unsolvable. As McManus (1995) suggests "enlightenment is a valuable aid to seeing problems not as opaque and oppressive but interesting puzzle to be solved - even if we conclude that on some levels no direct actions is possible." Being the teachers, the controller of the classroom, we must have the confidence to solve the problem. 
In order to understand the behaviour of the children, the teachers should imagine they are in the positions of the students', thinking about themselves what they will do? And then "pre-empting" the student misbehaviour- "minimise its occurrence in the first place" (Kyriacou, 1997) to ensure the quality of the educational progress. Once the behaviour occurs, teachers' action should move along a continuum according to the seriousness of the misbehaviour. Before using punishments make sure the other action has been used without effectiveness because punishment, as the most serious action for the student misbehaviour, can cause confrontations between the teacher and the students if they are not been used appropriately. Rewards, as a positive classroom control action, can help to rebuild students' self-esteem, and solve the problem from the roots.

I would like to stress here that trying to build a positive student-teacher relationship can effectively minimise the chances of the happening of student misbehaviour, and also, it can solve the problem easier. Teachers should try be friends of the students after the teachers" authority has been established. Teachers should also judge their position in the classroom as a kind and warm person to adjust the behaviour of the students but not a strict adult charger.

All in all, the appropriate steps for dealing with student misbehaviour in the classroom are: understand it completely, think about it carefully and deal with it intelligently. The quality of the teaching and learning progress can be assured when student misbehaviour can be controlled effectively.

\section{References}

Adams, J. et al. (1999). Problems of behaviour, reading and arithmetic: assessments of comorbidity using the Strengths and Difficulties Questionnaire. British Journal of Education Psychology, 69 (4), 571-585. http://dx.doi.org/10.1348/000709999157905

Adelman, Howard S., \& Taylor, Linda. (1990). Intrinsic motivation and school misbehavior: some intervention implications. Journal of Learning Disabilities, 23 (9), 541-550.

Cooper, P. Smith, C., \& Upton, G (1994). Emotional and Behavioural Difficulties. London: Routledge.

Dean, J (2000). Improving Children's Learning: Effective teaching in the primary school. London: Routledge.

Elias, Habibah; Mahyuddin, Rahil \& Noordin, Nooreen (2009). Understanding the misbehavior of at-risk students: contributing factors. International Journal of the Humanities, 7 (4), 133-143.

Eslea, M. (1999). Attributional styles in boys with severe behavioural problems: a possible reason for locks of progress on a positive behaviour programme. British Journal of Educational Psychology, 69 (1), 33-45. http://dx.doi.org/10.1348/000709999157554

Fontana, D. (1994). Managing Classroom Behaviour. (2 ${ }^{\text {nd }}$ ed.). London: Routledge.

Gray, J., \& Richer J. (1988). Classroom Responses to Disruptive Behaviour. London: Macmillan Education.

Hollin, C. (1993). Social reasons for bad behaviour. In Varma. (ed.) (1993) Management of Behaviour in Schools (pp 66-88). London: Longman.

Jones, D. (1993). Behaviour approaches to the management of difficult behaviour. In Varma, V. (ed.) (1993) Management of Behaviour in Schools (pp 21-36). London: Longman.

Kyriacou, C. (1997). Effective Teaching in Schoos. (2 ${ }^{\text {nd }}$ ed.). Cheltenham: Nelson Thornes.

Kyriacou, C. (1998). Essential Teaching Skills. (2 ${ }^{\text {nd }}$ ed.). Cheltenham: Nelson Thornes.

Long, M. (2000). The Psychology of Education. London: RoutledgeFalmer. Chapters 10 and 11.

McManus, M. (1993). Discipline in students exclude from school. In Varma, V. (ed.) (1993) Management of Behaviour in Schools (pp218-232). London: Longman.

Mcmanus, M. (1995). Troublesome Behaviour in the Classroom. (2 ${ }^{\text {nd }}$ ed.). London: Routledge.

McNamara, E. (2000). Positive Student Management and Motivation. London: David Fulton.

Merrett, F., \& Wheldall, K. (1990). Positive Teaching in the Primary School. London: Paul Chapman.

Miller, A., Ferguson, E., \& Simpson, R. (2002). Parents' and students' causal attributions for difficult classroom behaviour, British Journal of Education Psychology, 72(1), 27-40. http://dx.doi.org/10.1348/000709902158757

Munn, P. Johnstone, M., \& Chalmers, V. (1992). Effective Discipline in Secondary Schools and Classrooms. London: Paul Chapman.

Robertson, J. (1996). Effective Classroom Control. ( $3^{\text {rd }}$ ed.). London: Hodder and Stoughton. 
Rogers, B. (2002). Classroom Behaviour. London: Paul Chapman.

Rogers, B. (1997) .The Language of Discipline. 2nd edition. Plymouth: Northcote House.

Rogers. B. (1995). Behaviour Management. Sydney: Scholastic.

Stephens, P., \& Crawley, T. (1994). Becoming an Effective Teacher. Cheltenham: Nelson Thornes.

Varma, V. (ed.) (1993). Management of Behaviour in Schools. London: Longman.

Waterhouse, P. (1983). Managing the Learning Process. London: McGraw-Hill

Table 1. Classroom disruption

\begin{tabular}{|l|l|l|}
\hline Type of student behaviour & \multicolumn{2}{|c|}{ Frequency during lessons } \\
\hline & At least weekly (\%) & At least daily (\%) \\
\hline Talking out of turn & 97 & 53 \\
\hline Idleness or work avoidance & 87 & 25 \\
\hline Hindering other students & 86 & 26 \\
\hline Unpunctuality & 82 & 17 \\
\hline Unnecessary noise & 77 & 25 \\
\hline Breaking school rules & 68 & 17 \\
\hline Out-of-seat behaviour & 62 & 14 \\
\hline Verbal abuse of other students & 62 & 10 \\
\hline General rowdiness & 61 & 10 \\
\hline Impertinence & 58 & 10 \\
\hline Physical aggression to other students & 42 & 6 \\
\hline Verbal abuse of teacher & 15 & 1 \\
\hline Physical destructiveness & 14 & 1 \\
\hline Physical aggression towards teacher & 0.17 & 0 \\
\hline
\end{tabular}

(Adapted from The Elton Report, DES, 1989. cited in Fontana, 1994)

Silently looking on

तु

Non-directive statements

$\sqrt{3}$

Questions

तु

Directive statements

\&

Modelling

ת

Reinforcement

ת

Physical intervention and isolation

Figure 1. Teacher behaviour continuum

Sources: from Wolfgang and Glickman (1986, cited in Cooper et al, 1994) 